\title{
Association Between Serum Uric Acid And Major Chronic Diseases Among Centenarians In China: Based On The CHCCS Study
}

\section{Fuyin Kou}

Chinese PLA general hospital

\section{Shanshan Yang}

Chinese PLA general hospital

\section{Shengshu Wang}

Chinese PLA general hospital

Miao Liu ( $\nabla$ liumiaolmbxb@163.com )

Chinese PLA general hospital https://orcid.org/0000-0002-7975-6702

\section{Yao He}

Chinese PLA General Hospital

\section{Research article}

Keywords: Serum uric acid, Hyperuricemia, Dyslipidemia, Centenarian

Posted Date: January 15th, 2021

DOI: https://doi.org/10.21203/rs.3.rs-144627/v1

License: (c) (1) This work is licensed under a Creative Commons Attribution 4.0 International License. Read Full License

Version of Record: A version of this preprint was published at BMC Geriatrics on April 7th, 2021. See the published version at https://doi.org/10.1186/s12877-021-02185-y. 


\section{Abstract}

Introduction: This study aims to analyze the distribution of SUA level based on more than 1,000 centenarians and to explore the association with three common diseases including hypertension, diabetes and dyslipidemia.

Methods: All the 1002 centenarians from the CHCCS were included. Household survey was conducted.

Results: The mean SUA level of centenarians was $329.04 \pm 97.75 \mu \mathrm{mol} / \mathrm{L}$ and the prevalence of hyperuricemia in centenarians was $26.5 \%$. There was no statistical difference in the distribution of SUA levels among centenarians with or without hypertension/diabetes. For dyslipidemia, there was an independent positive association. The risk of dyslipidemia among those with hyperuricemia were 1.646 (95\%Cl: 1.078-2.298) compared with those who didn't have hyperuricemia. By comparing different subtypes of dyslipidemia, hyperuricemia was positively associated with hypertriglyceridemia and lowdensity lipoprotein cholesterolemia, with the corresponding ORs of 2.553 (95\% Cl: 1.282-5.083) and 1.927 (95\%Cl: 1.273-2.917) respectively, while there was no statistically significant association with hypercholesterolemia 0.998 (95\% Cl: 0.574-1.732).

Conclusions: There was no relation between SUA with hypertension or diabetes, while there was independently and positively association with hypertriglyceridemia and low-density lipoprotein cholesterolemia. The health benefits of controlling SUA in centenarians still require evidence based on prospective studies.

\section{Introduction}

Serum uric acid (SUA) is an important index of renal function. It is the product of protein metabolism ${ }^{1}$. The current physiological reference value of SUA was mainly from data about adults ${ }^{2-4}$. However, it is well known kidney function deteriorates with age. The renal function of centenarians is far worse than that of adults and young elderly. But there is little data on the mean level of SUA about this extremely survivors ${ }^{6}$. Whether it is the same as the general elderly, or as a template for healthy aging, which is worth discussing.

On the other hand, SUA is not only an indicator of renal function, but also an important risk factor for cardiovascular disease and metabolic diseases. Meta-analysis showed that SUA was a risk factor for hypertension, metabolic syndrome, and coronary heart diseases ${ }^{7-8}$. Therefore, SUA has become one of the indicators for early warning and intervention of major chronic diseases including cardiovascular diseases. However, the current evidence is mostly about adults, a small part was from younger elderly aged $<80$ years old. There was a lack of basic data for centenarians. Whether this trend still exists among centenarians is unknown. That is to say, in centenarians, whether SUA is still an important risk factor for major diseases and needs to be controlled, there is no sufficient evidence yet. So, this study used data from one of Asia's largest centenarian survey to analyze the distribution of SUA level based on more than 
1,000 centenarians and to explore the association with three common diseases including hypertension, diabetes and dyslipidemia.

\section{Research Design And Methods}

\section{Study population}

All the subjects in this study were from CHCCS, and the detailed research design framework was shown in previous articles 9 . In brief, this was a full sample survey. Based on the demographic data of 18 cities of Hainan Province provided by the Civil Affairs Bureau, we included all the people aged 100 and over in the study. A total of 1002 centenarians were invited to the survey and include in the analysis.

\section{Investigation method}

Household survey was conducted. All the questions on the questionnaire were asked and recorded by trained investigators. Centenarians were asked to answer health-related questions themselves. For those who were unable to answer the questions, the caregivers or relatives should answer on their behalf. All investigators were medical staff from Hainan hospital of Chinese PLA general hospital and have received unified training. Unified questionnaires were used to collect detailed demographic characteristics, disease history, family history, and lifestyles. Measurement indicators include height (For those who have a pot, measure their length), weight, waist circumference (WC), and blood pressure. Elbow vein blood was taken at 7-8 a.m. (more than 8 hours of fasting), and sent to the biochemical division of Hainan hospital of Chinese PLA general hospital to test related biochemical index, including total cholesterol (TC), triglycerides (TG), high-density lipoprotein cholesterol (HDL-C), low-density lipoprotein cholesterol (LDL-C), fasting blood glucose (FPG), albumin (ALB), serum uric acid (SUC), creatinine (Scr), blood urea nitrogen (BUN).

\section{Definitions}

Centenarians referred to those who have certainly reached the age of 100 years old at the survey. Age was calculated by the survey minus the birth date. Body mass index (BMI) was calculated as weight (in kilograms) divided by the square of height (in meters).

Hyperuricemia was defined as positive if SUA level $\geq 420 \mu \mathrm{mol} / \mathrm{L}$ in men or $\geq 360 \mu \mathrm{mol} / \mathrm{L}$ in women or previous diagnosed.

Abdominal obesity was defined as positive if $W C \geq 90 \mathrm{~cm}$ in men or $W C \geq 80 \mathrm{~cm}$ in women.

Blood pressure was classified into the following categories: normal blood pressure: no history of hypertension in the past and SBP $<120$ and $\mathrm{DBP}<80 \mathrm{mmHg}$; prehypertension: no history of hypertension in the past and $120 \mathrm{mmHg}<\mathrm{SBP}<140 \mathrm{mmHg}$ or $80 \mathrm{mmHg}<\mathrm{DBP}<90 \mathrm{mmHg}$; Hypertension, previous diagnosis or $\mathrm{SBP} \geq 140 \mathrm{mmHg}$ or $\mathrm{DBP} \geq 90 \mathrm{mmHg}$. 
Blood glucose was classified into the following categories: normal blood glucose, no history of diabetes in the past and FPG $\geq 6.1 \mathrm{mmol} / \mathrm{L}$; Impaired fasting glucose (IFG), no history of diabetes in the past and $6.1 \mathrm{mmol} / \mathrm{L} \leq \mathrm{FPG}<7.0 \mathrm{mmol} / \mathrm{L}$; Diabetes, previous diagnosis or $\mathrm{FPG} \geq 7.0 \mathrm{mmol} / \mathrm{L}$.

Blood lipids was classified into the following categories: normal blood lipids, no history of dyslipidemia in the past and total cholesterol $(\mathrm{TC})<5.18 \mathrm{mmol} / \mathrm{L}$, triglyceride $(\mathrm{TG})<1.70 \mathrm{mmol} / \mathrm{L}$, high density lipoprotein cholesterol $(\mathrm{HDL}-\mathrm{C}) \geq 1.04 \mathrm{mmol} / \mathrm{L}$, and low density lipoprotein cholesterol $(\mathrm{LDL}-\mathrm{C})<3.37$ $\mathrm{mmol} / \mathrm{L}$; elevated blood lipids: no history of dyslipidemia in the past and $5.18 \mathrm{mmol} / \mathrm{L} \leq \mathrm{TC}<6.22 \mathrm{mmol} / \mathrm{L}$, $1.70 \mathrm{mmol} / \mathrm{L} \leq \mathrm{TG}<2.26 \mathrm{mmol} / \mathrm{L}$, and $3.37 \mathrm{mmol} / \mathrm{L} \leq \mathrm{LDL}-\mathrm{C}<4.14 \mathrm{mmol} / \mathrm{L}$; dyslipidemia, previous diagnosis or $\mathrm{TC} \geq 6.22 \mathrm{mmol} / \mathrm{L}$, or $\mathrm{TG} \geq 2.26 \mathrm{mmol} / \mathrm{L}$, or $\mathrm{HDL}-\mathrm{C}<1.04 \mathrm{mmol} / \mathrm{L}$, or LDL-C $\geq 4.14 \mathrm{mmol} / \mathrm{L}$. The subtypes of dyslipidemia were classified into the following categories: Hypercholesterolemia, $\mathrm{TC} \geq 6.22 \mathrm{mmol} / \mathrm{L}$; Hypertriglyceridemia, TG $\geq 2.26 \mathrm{mmol} / \mathrm{L}$; Combined hyperlipidemia, TC $\geq 6.22 \mathrm{mmol} / \mathrm{L}$ and $T G \geq 2.26 \mathrm{mmol} / \mathrm{L}$; low-density lipoprotein cholesterolemia, HDL-C $<1.04 \mathrm{mmol} / \mathrm{L}$.

\section{Patient and Public Involvement}

All centenarians were from Hainan Province. The investigation group obtained the list of centenarians from the Civil Affairs Department, and conducted household survey on those who agreed to participate in the survey. Health related information of the centenarians were collected by face-to-face questionare. All the centenarians were told and aware of the design and purpose of the study and participated in the study after signing informed consent. The results of laboratory test and physical examination should be fed back to the elderly in time.

\section{Statistical analysis}

All the analysis was conducted in SPSS 20.0(SPSS Inc., Chicago, IL). Mean \pm SD and n(\%) were used for continuous and categorical variables. Variance analysis and chi-square test were used for comparisons among different groups. Pearson correlation coefficients were used to describe correlations between SUA levels and other variables. Multivariate logistic regression was used to calculate the odds ratio (OR) of SUA for related diseases. As the independent variable, SUA was included in the model as two forms: continuous value and binary variable (hyperuricemia). Three diseases were considered as dependent variables, including hypertension, diabetes and dyslipidemia. We also used prehypertension/hypertension, IFG/diabetes, elevated lipids/dyslipidemia as dependent variables for sensitivity analysis. Covariates including demographic sociological characteristics (gender, age, ethnicity, culture, marriage, and previous work type), lifestyle (smoking, drinking, physical exercise, and dietary habits), and abdominal obesity were included in the logistic regression model.

\section{Results}

The mean age was $102.77 \pm 2.55$ years, with $82.0 \%$ were female. WC, TG, and HDL-C were related with SUA levels $(p<0.05)$. Correspondingly, there were statistical differences with abdominal obesity and dyslipidemia prevalence (table 1). 


\section{Distribution of SUA levels and prevalence of hyperuricemia}

The mean SUA level of centenarians was $329.04 \pm 97.75 \mu \mathrm{mol} / \mathrm{L}$. $45.7 \%$ of them were between $250-350$ $\mu \mathrm{mol} / \mathrm{L}$ and $81.4 \%$ were between $200-450 \mu \mathrm{mol} / \mathrm{L}$. Only $5.7 \%$ were under $200 \mu \mathrm{mol} / \mathrm{L}$ and $11.0 \%$ were $>450 \mu \mathrm{mol} / \mathrm{L}$ (appendix table 1).

The mean SUA level was higher among male than that of female $(379.86 \pm 110.08 \mu \mathrm{mol} / \mathrm{L}$ vs. $317.91 \pm 9.19 \mu \mathrm{mol} / \mathrm{L}, \mathrm{p}<0.001)$. Compared with different age groups, the mean SUA levels were basically the same for each 5 years' age group (100-104, 105-109, 110- ). That is, there was no increasing or decreasing trend of SUA levels with age.

The prevalence of hyperuricemia in centenarians was $26.5 \%$. Male had a relatively higher prevalence than that in female, although not statistically significant $(30.0 \%$ vs. $25.8 \%, p=0.247)$. Similarly, there was no age-related trend $(p=0.361)$. (table 2$)$

\section{Correlation analysis of SUA levels and three common diseases}

As can be seen from table 3, SUA level was positively correlated with Scr and BUN level, with the Pearson's correlation coefficients 0.528 and 0.389 respectively $(p<0.05)$. In addition, SUA level was positively correlated with obesity related indicators, including weight and WC, with the Pearson's correlation coefficients 0.228 and 0.188 respectively $(p<0.05)$. The Pearson's correlation coefficients of SUA with systolic blood pressure (SBP), diastolic blood pressure (DBP), blood glucose were $-0.003,-0.056$ and -0.001 respectively $(p>0.05)$. On the other hand, SUA level was related with blood lipid, including TG $(r=0.119, p<0.05)$ and HDL-C $(r=-0.101, p<0.05)$, but not with TC $(r=-0.006, P 0.847)$ and LDL-C $(r=0.027$, $p=0.401)$.

\section{Association between SUA levels and three common diseases}

There was no statistical difference in the distribution of SUA levels among centenarians with or without hypertension. The mean SUA level for the three groups (normal blood pressure, pre-hypertension and hypertension) were $335.30 \pm 91.33 \mu \mathrm{mol} / \mathrm{L}, 321.53 \pm 87.46 \mu \mathrm{mol} / \mathrm{L}$ and $330.30 \pm 100.69 \mu \mathrm{mol} / \mathrm{L} p=0.473$ ) respectively (appendix table 2). The situation was similar with diabetes. The mean SUA level for the three groups (normal blood glucose, IFG and diabetes) were $328.84 \pm 95.58 \mu \mathrm{mol} / \mathrm{L}, 329.35 \pm 87.13 \mu \mathrm{mol} / \mathrm{L}$, $330.49 \pm 122.62 \mu \mathrm{mol} / \mathrm{L}, \mathrm{p}=0.987)$. There was statistical difference among different blood lipids groups. The mean SUA level for the three groups (normal blood lipids, elevated blood lipids and dyslipidemia) were $311.87 \pm 90.91 \mu \mathrm{mol} / \mathrm{L}, 325.19 \pm 89.63 \mu \mathrm{mol} / \mathrm{L}$ and $357.2 \pm 116.92 \mu \mathrm{mol} / \mathrm{L}, \mathrm{p}<0.001)$ respectively.

Table 4 showed the result of multivariate logistic regression analysis of the association between SUA level and three common diseases. Hypertension, diabetes and dyslipidemia were used as dependent variables separately; SUA level was used as the independent variable; the related covariates including demographic variables, lifestyles, disease history were also adjusted included in the model. As can be seen from Table 4, SUA levels was not associated with hypertension, the ORs were 1.000 ( $95 \% \mathrm{Cl}$ : 0.999 1.002) and 1.221 (95\%Cl: 0.874-1.707) when the independent SUA levels as continuous variable and 
dichotomous variable (hyperuricemia). Similarly, SUA levels was not associated with diabetes either, the ORs were 1.000 (95\% Cl: 0.998-1.002) and 1.290 (95\% Cl: 0.818-2.037) respectively. For dyslipidemia, there was an independent positive association. The risk of dyslipidemia among those with hyperuricemia were 1.646 (95\% Cl: 1.078-2.298) compared with those who didn't have hyperuricemia. By comparing different subtypes of dyslipidemia, hyperuricemia was positively associated with hypertriglyceridemia and lowdensity lipoprotein cholesterolemia, with the corresponding ORs of 2.553 (95\% Cl: 1.282-5.083) and 1.927 (95\%Cl: 1.273-2.917) respectively, while there was no statistically significant association with hypercholesterolemia 0.998 (95\% Cl: 0.574-1.732).

\section{Discussion}

This result based on CHCCS showed that the prevalence of hyperuricemia in centenarians was high, and it had independently and positively association with hypertriglyceridemia and low density lipoprotein cholesterolemia while no association with hypertension or diabetes.

SUA level was higher than that of adults and younger elderly. The prevalence of hyperuricemia was also at a high level among centenarians. Previous study based on 22983 Chinese adults based on Chinese Physiological Constant and Health Conditions Study showed that the average SUA level in Chinese population was $346.1 \mathrm{umol} / \mathrm{L}$ and $258.6 \mathrm{umol} / \mathrm{L}$ for males and females respectively. The prevalence of hyperuricemia was $13.0 \%$, while the prevalence went up to $20.5 \%$ among elderly ${ }^{10}$. The study based on elderly from Beijing showed the mean SUA levels were $345.1 \mathrm{umol} / \mathrm{L}$ and $309.4 \mathrm{umol} / \mathrm{L}$ in male and female respectively, and the prevalence of hyperuricemia was $16.7 \%{ }^{11}$. The meta-analysis based on 38 studies showed that the prevalence of hyperuricemia in Chinese people was $13.3 \%$. This study showed that the mean SUA level was $329.04 \mu \mathrm{mol} / \mathrm{L}$ in centenarians, which was higher than previous studies based on adults or younger elderly ${ }^{12}$. Male had slightly higher SUA levels than female, but there was no statistical difference, which was consistent with previous results ${ }^{13}$. Meta-analysis showed that the gender difference of hyperuricemia prevalence narrowed among people aged 50 and over ${ }^{12}$. It's partly because that with the decrease of estrogen after menopause, female lose the protective effects.

There was no relation between SUA with hypertension or diabetes, which was inconsistent with previous studies based on adults or younger elderly. Meta-analysis based on 18 cohort studies with 55607 people showed that the risk of hypertension among hyperuricemia patients were $1.41(95 \% \mathrm{Cl}: 1.23-1.58)^{14}$. Another meta-analysis based on 16 cohort study with 61714 people showed that the risk of diabetes among hyperuricemia patients were $1.131\left(95 \% \mathrm{Cl}\right.$ : 1.084-1.179) ${ }^{15}$. However, the above meta-studies only included data on adults and people less than 80 , and lacked data on centenarians. The association between SUA and diabetes or hypertension tends to weaken with the increase of age. The results from the Project of Longevity and Aging in Dujiangyan study also showed that SUA was not directly associated with hypertension based on 870 nonagenarians/centenarians ${ }^{6}$. Results from Health Professionals Follow-Up Study also showed similar results based on elderly men aged $60-85^{16}$. These results were consistent with the conclusion of our study. On the other hand, this study showed that SUA was 
independently and positively correlated with hypertriglyceridemia and low-density lipoprotein cholesterolemia. A 5-year cohort study of 6476 adults from Japan showed that the risk of low-density lipoprotein cholesterolemia for every $1 \mathrm{mg} / \mathrm{dL}$ increase in SUA level was 1.159 (95\% Cl: 1.009-1.331) in male and 1.215 (95\% Cl: 1.061-1.390) in female respectively ${ }^{17}$. Another study based on the results of 8year follow-up of 4190 adults, the incidence of hypertriglyceridemia was $28.2 \%, 29.1 \%, 36.9 \%$ and $45.6 \%$ respectively with the quartile of SUA level ${ }^{18}$. Those results were consistent with this study, which was the first to analyze the association of SUA with dyslipidemia and tis subtypes (including hypertriglyceridemia and low-density lipoprotein cholesterolemia) in centenarians. The results showed that there was a significant positive correlation between SUA and hypertriglyceridemia and low-density lipoprotein cholesterolemia.

Our study has several strengths. This is the largest centenarian study in Asia with good representativeness. Second, unlike other sociological surveys that focus on sociology and less focus on health-related issues, this CHCCS survey was conducted by professional medical staff, which provided reliable and sufficient medical information. Third, we analyzed the association between SUA with all three common chronic diseases at the same time, which may be helpful for the comparisons.

Also, this study had several limitations. First, this was a cross-sectional study with limited causal inference, and the strength of causal inference is low, which still needs to be verified by prospective research. Second, SUA was a one-time test, which may be affected by diet and other factors. Third, lack of information about drug use may have an impact on the outcome. But, according to the appendix table 3 , there was less than $1 / 4$ of the centenarians who were taking medicine. Fourth, there may be survivor bias; the centenarians surveyed were relatively healthy people, which may underestimate the risk.

\section{Conclusion}

In summary, the results based on CHCCS with the largest sample among centenarians showed that centenarians had higher SUA levels and higher hyperuricemia prevalence. There was no relation between SUA with hypertension or diabetes, while there was independently and positively association with hypertriglyceridemia and low-density lipoprotein cholesterolemia. The health benefits of controlling SUA in centenarians still require evidence based on prospective studies.

\section{Abbreviations}

ALB, albumin; BL, blood lipids; BMI, body mass index; BUN, serum urea nitrogen; $\mathrm{Cl}$, confidence interval; CHCCS, China Hainan Centenarian Cohort Study; DBP, diastolic blood pressure; FBG, fasting plasma glucose; HDL-C, high density lipoprotein cholesterol; IFG, impaired fasting glucose; LDL-C, low density lipoprotein cholesterol; OR, odds ratio; SBP, systolic blood pressure; Scr, serum creatinine; SUA, serum uric acid; TC, total cholesterol; TG, triglyceride;

\section{Declarations}


Acknowledgments

We thank the staff and participants of the China Hainan Centenarian Cohort Study (CHCCS).

\section{Contributors}

All authors were involved in the design of the study, statistical analysis, interpretation of the data, drafting of the manuscript.

\section{Funding}

This work was supported by Special Foundation for the Cultivation of Excellent Youth Science in PLA General Hospital (2017-YQPY-003), Beijing Nova Program (Z181100006218085), National Natural Science Foundation of China $(81773502,81703285)$, Opening Foundation of State Key Laboratory of Kidney Diseases (KF-01-115), Opening Foundation of National Clinical Research Center of Geriatrics (NCRCG-PLAGH-2017017), Beijing Natural Science Foundation (7174350), Military Fund (15BJZ41, 17BJZ51), Medical Big Data Fund of Chinese PLA General Hospital (2018MBD-029). The views and opinions expressed in this paper are those of the authors and do not necessarily reflect the official position of the study sponsors.

Patient and public involvement Patients and/or the public were not involved in the design, or conduct, or reporting, or dissemination plans of this research.

\section{Competing interests}

None declared.

\section{Consent for publication}

Not required.

\section{Ethics approval}

This study was approved by the Biomedical Ethics Committee of Chinese PLA general hospital, and written informed consent with signature or fingerprint was obtained from each respondent.

\section{Data availability statement}

The datasets used during the current study are available on reasonable request.

\section{References}

1. Athyros VG, Mikhailidis DP, Liberopoulos EN, et al. Effect of statin treatment on renal function and serum uric acid levels and their relation to vascular events in patients with coronary heart disease 
and metabolic syndrome A subgroup analysis of the GREek Atorvastatin and Coronary heart disease Evaluation. Nephrol Dial Transplant. 2007,22:118-27.

2. Hak A E, Choi H K. Menopause, postmenopausal hormone use and serum uric acid levels in US women - The Third National Health and Nutrition Examination Survey. Arthritis research \& therapy, 2008,10: R116.

3. Desideri G, Castaldo G, Lombardi A, et al. Is it time to revise the normal range of serum uric acid levels? European Review for Medical \& Pharmacological Sciences, 2014, 18:1295-306.

4. Mikkelsen $\mathrm{W} M$, Dodge $\mathrm{H} \mathrm{J}$, Valkenburg $\mathrm{H}$. The distribution of serum uric acid values in a population unselected as to gout or hyperuricemia: tecumseh, michigan 1959-1960. American Journal of Medicine, 1965, 39:242-251.

5. Shlipak MG, Katz R, Kestenbaum B, et al. Clinical and subclinical cardiovascular disease and kidney function decline in the elderly. Atherosclerosis, 2009,204: 298-303.

6. Lu Z, Dong B, Wu H, et al. Serum uric acid level in primary hypertension among Chinese nonagenarians/centenarians. Journal of Human Hypertension, 2009,23: 113-121.

7. Gonçalves JP, Oliveira A, Severo M, et al. Cross-sectional and longitudinal associations between serum uric acid and metabolic syndrome. Endocrine, 2012, 41: 450-457.

8. Qin L, Yang Z, Gu H, et al. Association between serum uric acid levels and cardiovascular disease in middle-aged and elderly Chinese individuals. BMC Cardiovascular Disorders, 2014, 14: 26.

9. He Y, Zhao Y, Yao Y, et al. Cohort Profile: The China Hainan Centenarian Cohort Study (CHCCS). International Journal of Epidemiology, 2018, 47:1-10.

10. Zhu GJ. Physiological Constants and Psychological Status of Chinese Population. 2006, Beijing: China Union Medical University Press.

11. Liu $\mathrm{M}$, Wang JH, Zeng J, et al. Relationship between serum uric acid level and mild cognitive impairment in Chinese community elderly. BMC Neurology, 2017,7: 146.

12. Rui L, Cheng H, Di W, et al. Prevalence of Hyperuricemia and Gout in Mainland China from 2000 to 2014: A Systematic Review and Meta-Analysis. Biomed Research International, 2015,2015: 1-12.

13. Liu H, Zhang XM, Wang YL, et al. Prevalence of hyperuricemia among Chinese adults: a national cross-sectional survey using multistage, stratified sampling. Journal of Nephrology, 2014, 27:653658.

14. Grayson PC, Kim SY, LaValley M, et al. Hyperuricemia and incident hypertension: a systematic review and meta-analysis. Arthritis Care \& Research, 2011, 63: 102-110.

15. Xu YL, Xu KF, Bai JL, et al. Elevation of serum uric acid and incidence of type 2 diabetes: $A$ systematic review and meta-analysis. Chronic Dis Transl Med., 2016, 2:81-91.

16. Forman, J, Choi H, Curhan GC. Plasma uric acid level and risk for incident hypertension among men. Journal of the American Society of Nephrology, 2007, 18: 287-292.

17. Kuwabara M, Borghi C, Cicero AFG, et al. Elevated serum uric acid increases risks for developing high LDL cholesterol and hypertriglyceridemia: A five-year cohort study in Japan. International Journal of 
Cardiology, 2018,261: 183-188.

18. Zheng R, Ren P, Chen Q, et al. Serum Uric Acid Levels and Risk of Incident Hypertriglyceridemia: A Longitudinal Population-based Epidemiological Study. Annals of Clinical \& Laboratory Science, 2017:47: 586-591.

\section{Tables}

Table1. General characteristics of centenarians 


\begin{tabular}{|c|c|c|c|}
\hline & Hyperuricemia & & \\
\hline Characteristics & Yes & No & $\mathrm{p}$ \\
\hline \multicolumn{4}{|l|}{ mean $\pm S D$} \\
\hline Age (yrs) & $102.79 \pm 3.01$ & $102.76 \pm 2.65$ & 0.853 \\
\hline Weight(kg) & $38.72 \pm 8.18$ & $37.17 \pm 7.31$ & 0.004 \\
\hline $\mathrm{WC}(\mathrm{cm})$ & $77.01 \pm 8.95$ & $74.53 \pm 8.74$ & $<0.001$ \\
\hline $\mathrm{BMI}\left(\mathrm{kg} / \mathrm{m}^{2}\right)$ & $18.37 \pm 3.47$ & $17.92 \pm 3.37$ & 0.271 \\
\hline $\mathrm{SBP}(\mathrm{mmHg})$ & $154.05 \pm 25.75$ & $152.03 \pm 23.93$ & 0.247 \\
\hline $\mathrm{DBP}(\mathrm{mmHg})$ & $75.01 \pm 12.68$ & $76.02 \pm 13.03$ & 0.276 \\
\hline $\mathrm{TC}(\mathrm{mmol} / \mathrm{l})$ & $4.64 \pm 0.99$ & $4.69 \pm 0.99$ & 0.459 \\
\hline $\mathrm{TG}(\mathrm{mmol} / \mathrm{l})$ & $1.27 \pm 0.75$ & $1.14 \pm 0.61$ & 0.005 \\
\hline $\mathrm{HDL}-\mathrm{C}(\mathrm{mmol} / \mathrm{l})$ & $1.39 \pm 0.43$ & $1.45 \pm 0.37$ & 0.041 \\
\hline LDL-C(mmol/l) & $2.81 \pm 0.82$ & $2.81 \pm 0.78$ & 0.926 \\
\hline $\mathrm{FPG}(\mathrm{mmol} / \mathrm{I})$ & $5.18 \pm 1.46$ & $5.10 \pm 1.44$ & 0.466 \\
\hline $\operatorname{ALB}(g / L)$ & $38.42 \pm 3.88$ & $38.52 \pm 4.05$ & 0.734 \\
\hline $\operatorname{SUA}(\mu \mathrm{mol} / \mathrm{L})$ & $450.04 \pm 76.59$ & $285.31 \pm 60.69$ & $<0.001$ \\
\hline \multicolumn{4}{|l|}{$n(\%)$} \\
\hline Gender & & & 0.247 \\
\hline Male & $54(30.0)$ & $126(70.0)$ & \\
\hline Female & 212(25.8) & $610(74.2)$ & \\
\hline Nationality & & & 0.330 \\
\hline Han & $230(26.0)$ & 653(74.0) & \\
\hline Minority & $36(30.3)$ & $83(69.7)$ & \\
\hline Marriage status & & & 0.343 \\
\hline Widowed & $217(26.0)$ & 619(74.0) & \\
\hline Married/divorced/others & $49(29.5)$ & 117(70.5) & \\
\hline Education level & & & 0.880 \\
\hline Illiteracy & $241(26.3)$ & 674(73.7) & \\
\hline Primary school & 19(28.4) & $48(71.6)$ & \\
\hline
\end{tabular}




\begin{tabular}{|c|c|c|c|}
\hline Middle school or above & $6(30.0)$ & $14(70.0)$ & \\
\hline Work types & & & 0.410 \\
\hline Mental work & $8(34.8)$ & $15(65.2)$ & \\
\hline Light or moderate physical labor & $148(27.6)$ & $388(72.4)$ & \\
\hline Heavy physical labor & $110(24.8)$ & $333(75.2)$ & \\
\hline Smoking & & & 0.665 \\
\hline Never smoking & $236(26.3)$ & $660(73.7)$ & \\
\hline Ever or current smoking & $30(28.3)$ & 76(71.7) & \\
\hline Alcohol drinking & & & 0.086 \\
\hline Never alcohol drinking & $213(25.5)$ & $623(74.5)$ & \\
\hline Ever or current alcohol drinking & $53(31.9)$ & 113(68.1) & \\
\hline Vegetables( $\geq 1$ time/day) & & & 0.641 \\
\hline Yes & $236(26.8)$ & $645(73.2)$ & \\
\hline No & $30(24.8)$ & $91(75.2)$ & \\
\hline Fruits( $\geq 1$ time/day) & & & 0.335 \\
\hline Yes & $41(29.9)$ & $96(70.1)$ & \\
\hline No & $225(26.0)$ & $640(74.0)$ & \\
\hline Meat( $\geq 1$ time/day) & & & 0.568 \\
\hline Yes & $92(25.5)$ & $269(74.5)$ & \\
\hline No & $174(27.1)$ & $467(72.9)$ & \\
\hline Fish( $\geq 1$ time/day) & & & 0.397 \\
\hline Yes & $81(24.8)$ & $245(75.2)$ & \\
\hline No & $185(27.4)$ & $491(72.6)$ & \\
\hline Eggs( $\geq 1$ time/day) & & & 0.054 \\
\hline Yes & $26(27.4)$ & $69(72.6)$ & \\
\hline No & $250(27.6)$ & $657(72.4)$ & \\
\hline Milk( $\geq 1$ time/day) & & & 0.774 \\
\hline Yes & $31(27.7)$ & $81(72.3)$ & \\
\hline No & $235(26.4)$ & 655(73.6) & \\
\hline
\end{tabular}




\begin{tabular}{|llll|}
\hline Abdominal obesity & & 0.002 \\
\hline No & $81(34.2)$ & $156(65.8)$ & \\
\hline Hypertension & $185(24.2)$ & $580(75.8)$ & \\
\hline Yes & & & 0.222 \\
\hline No & $206(27.5)$ & $542(72.5)$ & \\
\hline Dyslipidemia & $60(23.6)$ & $194(76.4)$ & \\
\hline Yes & & & 0.001 \\
\hline No & $72(35.6)$ & $130(64.4)$ & \\
\hline Diabetes & $194(24.3)$ & $606(75.8)$ & \\
\hline Yes & & & 0.272 \\
\hline No & $30(31.3)$ & $66(68.8)$ & \\
\hline
\end{tabular}

Table 2. Distribution of SUA levels and hyperuricemia prevalence 


\begin{tabular}{|lllll|}
\hline & Male & Female & $p$ & Total \\
\hline SUA $(\mu \mathrm{mol} / \mathrm{L})$ & & & & \\
\hline Age groups & & & & \\
\hline $100-104$ yrs & $379.18 \pm 113.48$ & $319.29 \pm 89.34$ & $<0.001$ & $330.59 \pm 97.16$ \\
\hline $105-109$ yrs & $383.27 \pm 92.75$ & $311.11 \pm 100.28$ & $<0.001$ & $323.41 \pm 102.46$ \\
\hline$\geq 110$ yrs & - & $321.39 \pm 85.96$ & & $321.39 \pm 85.96$ \\
\hline P & 0.853 & 0.606 & & 0.615 \\
\hline Total & $379.86 \pm 110.08$ & $317.91 \pm 91.19$ & & $329.04 \pm 97.75$ \\
\hline Hyperuricemia [n(\%)] & & & & \\
\hline Age groups & & & 0.682 & $212(26.7)$ \\
\hline $100-104$ yrs & $42(28.0)$ & $170(26.4)$ & 0.059 & $43(24.4)$ \\
\hline $105-109$ yrs & $12(40.0)$ & $31(21.2)$ & - & $11(35.5)$ \\
\hline$\geq 110$ yrs & - & $11(35.5)$ & 0.361 \\
\hline P & 0.190 & 0.356 & $212(25.8)$ & $266(26.5)$ \\
\hline Total & $54(30.0)$ & 217 & & \\
\hline
\end{tabular}

Table3. Correlation analysis 


\begin{tabular}{|lll|}
\hline Vararibles & $r$ & $p$ \\
\hline Age $(\mathrm{yrs})$ & -0.020 & 0.529 \\
\hline Weight $(\mathrm{kg})$ & 0.228 & $<0.001$ \\
\hline $\mathrm{WC}(\mathrm{cm})$ & 0.188 & $<0.001$ \\
\hline $\mathrm{BMI}\left(\mathrm{kg} / \mathrm{m}^{2}\right)$ & 0.114 & $<0.001$ \\
\hline $\mathrm{SBP}(\mathrm{mmHg})$ & -0.003 & 0.918 \\
\hline $\mathrm{DBP}(\mathrm{mmHg})$ & -0.056 & 0.076 \\
\hline $\mathrm{TC}(\mathrm{mmol} / \mathrm{l})$ & -0.006 & 0.847 \\
\hline $\mathrm{TG}(\mathrm{mmol} / \mathrm{l})$ & 0.119 & $<0.001$ \\
\hline $\mathrm{HDL}-\mathrm{C}(\mathrm{mmol} / \mathrm{l})$ & -0.101 & $<0.001$ \\
\hline $\mathrm{LDL}-\mathrm{C}(\mathrm{mmol} / \mathrm{l})$ & 0.027 & 0.401 \\
\hline $\mathrm{FPG}(\mathrm{mmol} / \mathrm{l})$ & -0.001 & 0.967 \\
\hline $\mathrm{ALB}(\mathrm{g} / \mathrm{L})$ & 0.048 & 0.132 \\
\hline
\end{tabular}

Table 4. Multivariate analysis of SUA Level and major chronic diseases 


\begin{tabular}{|c|c|c|c|c|}
\hline \multirow[t]{2}{*}{ Independent variables } & \multicolumn{2}{|c|}{$\begin{array}{l}\text { SUA level (continuous, per } \\
\mu \mathrm{mol} / \mathrm{L} \text { ) }\end{array}$} & \multicolumn{2}{|c|}{ hyperuricemia(dichotomous) } \\
\hline & $\mathrm{OR}(95 \% \mathrm{Cl})$ & $\mathrm{p}$ & $\mathrm{OR}(95 \% \mathrm{Cl})$ & $p$ \\
\hline Hypertension & $1.000(0.999-1.002)$ & 0.286 & $1.221(0.874-1.707)$ & 0.242 \\
\hline $\begin{array}{l}\text { Prehypertension \& } \\
\text { hypertension }\end{array}$ & $1.000(0.997-1.002)$ & 0.578 & $1.115(0.650-1.912)$ & 0.691 \\
\hline Diabetes & $1.000(0.998-1.002)$ & 0.879 & $1.290(0.818-2.037)$ & 0.273 \\
\hline IFG\& diabetes & $1.000(0.998-1.002)$ & 0.995 & $1.255(0.878-1.793)$ & 0.213 \\
\hline Dyslipidemia & $1.003(1.002-1.005)$ & $<0.001$ & $1.646(1.078-2.298)$ & 0.003 \\
\hline Elevated BL\& Dyslipidemia & $1.001(1.000-1.002)$ & 0.142 & $1.201(1.001-1.594)$ & 0.024 \\
\hline Hypercholesterolemia & $1.001(0.999-1.004)$ & 0.222 & 0.998(0.574-1.732) & 0.993 \\
\hline Hypertriglyceridemia & $1.005(1.002-1.008)$ & 0.001 & $2.553(1.282-5.083)$ & 0.008 \\
\hline Combined hyperlipidemia & $1.007(1.002-1.011)$ & 0.005 & $\begin{array}{l}2.794(0.694- \\
11.252)\end{array}$ & 0.148 \\
\hline Low HDL-C & $1.004(1.002-1.006)$ & $<0.001$ & $1.927(1.273-2.917)$ & 0.002 \\
\hline
\end{tabular}

Adjusted for age, gender, nationality, education, marital status, BMI, work types, smoking, alcohol drinking, eating habits (vegetables, fruits, meat, fish, milk), abdominal obesity

\section{Supplementary Files}

This is a list of supplementary files associated with this preprint. Click to download.

- Appendixtables.docx 